\title{
Hybrid Shark Smell Optimization based on World Cup Optimization algorithm for Minimization of Total Harmonic Distortion
}

\author{
Yuanhao Liu \\ Faculty of Mechanical and Electrical Engineering, \\ Kunming University of Science and Technology, \\ Kunming, Yunnan Province, China \\ yuanhaoliu42@gmail.com
}

\begin{abstract}
Hybrid power generating system is well-known renewable energy equipment which is mostly intended for its consistent performance. Hence, this work develops a novel stage for power quality output by examining three DC-DC converters. This paper proposes to decrease Total Harmonic Distortion (THD) by presenting a hybrid power generation system using the integration of wind and solar power generation systems in addition to converters and full-bridge inverter. The examination is accomplished by linking converters such as SEPIC, buck-boost, Cuk converter for DC to DC level conversion. As the main objective, proportional gain, and Integral gain parameters of the PI controller, is optimized and this, to reduce the THD. For this optimization, this work develops a novel Hybrid SSO with WCO. The developed control system performance using optimization is evaluated with other existing techniques and it shows the dominance of the developed method.
\end{abstract}

Keywords: THD; PI Controller; SEPIC; DC-DC Converter; Cuk Converter; Optimization Algorithm

\begin{tabular}{ll} 
Nomenclature & \\
\hline Abbreviations & Descriptions \\
\hline THD & Total Harmonic Distortion \\
PEMFC & Proton Exchange Membrane Fuel Cell \\
PSO & Particle Swarm Optimization \\
PQ & Power Quality \\
SEPIC & Single-Ended Primary Inductor Converter \\
NTO & Nonlinear Transformational Optimization \\
SSO & Shark Smell Optimization \\
FRF & Frequency Response Function \\
GA & Genetic Algorithm \\
RBF & Radial Basis Function \\
WCO & World cup optimization \\
NN & Neural Network \\
\hline
\end{tabular}

\section{Introduction}

In the most recent few years, power electronic technologies have been developed widely for diverse applications like adjustable speed drivers, lighting, and uninterruptible power supply systems as a result of the sophisticated employ of semiconductor devices. This power electronics apparatus illustrates nonsinusoidal current and consequence harmonic distortion. The harmonic distortion can occur; be passive and active nonlinear devices in a power system. These days, the majority of harmonic distortion is produced by the input phase of electronic power converters. Because of the nonlinear structure, the majority power electronics apparatus illustrates nonsinusoidal current, and accordingly, consequences in important harmonic distortion in the power system have relentlessly deteriorated the PQ in electrical power networks. $\mathrm{PQ}$ encompasses turns out to be an important issue while distinguishing among 
flourishing utilities in the power network, particularly a deregulated environment. Harmonic analysis is a significant application to power systems as a competent technique to assess the injected THD.

THD is extensively exploited in audio system measurements able to imitate nonlinear targeted system behavior. In [13] initially suggest that analysis of THD can be utilized as a PEMFC conventional monitor. It was accounted for that cell serious position occurred by minimizing $\mathrm{O} 2$ stoichiometry is recognized through augmented THD signals underneath $30 \mathrm{~Hz}$. In a sense of application, the benefit of THD investigation is accredited to its minimum size and minimum cost. In [6] additional create a new obvious distinction among the EIS. Based on their description, allocation among CO-poisoned and the dehydrated circumstance of PEMFC cannot be attained using EIS. Nevertheless, second-order FRF is shown to be an effectual tool to create such a distinction.

The existing iterative method like Newton Raphson approaches can be exploited to resolve these nonlinear equations, excluding they necessitate an initial deduction of switching angles that is near to the precise solution [20]. Nevertheless, optimized discriminating harmonic exclusion based control is the viable option to the conventional control strategies. Hence, bio-inspired optimization techniques like PSO and GA based discerning harmonic elimination can be exploited to augment the stoutness of the system [19].

The most important purpose of this work is to propose hybrid power generating system and it is modelled by means of an amalgamation of wind and solar power generation system and converters and a full-bridge inverter. The examination is performed by linking DC to DC converters such as SEPIC, buckboost, and Cuk converter. Moreover, system THD is reduced by optimizing PI controller parameters such as Integral gain $\left(\mathrm{K}_{\mathrm{i}}\right)$ and proportional gain $\left(\mathrm{K}_{\mathrm{p}}\right)$. The optimization of Integral gain $\left(\mathrm{K}_{\mathrm{i}}\right)$ and the proportional gain $\left(\mathrm{K}_{\mathrm{p}}\right)$ is attained using a novel enhanced shark smell optimization algorithm indicated as enhanced-SSOA. Ultimately, the Hybrid SSO-WCO approach is used for each the converters, which is evaluated using the conventional techniques regarding the THD load voltage, and error.

\section{Literature Review}

In 2019, R Gunasekaran and Dr. C. Karthikeyan [1], developed an improvement process to index switching angles at essential frequency switching plan through executing NTO approach, similarly to decrease an individual line to line voltage harmonics, simultaneously, control over the degree of the output voltage of a multilevel inverter was specialist. The developed technique was implemented to such an extent that all probable strategy was obtained without meaningful appropriate start evaluation at the resolutions. Also, this process was sensible for further increased multilevel inverters to measure whereas additional conventional techniques lack interest in procedure the switching angles because of additional computational weight.

In 2018, N.J. Steffy et al [2], proposed a new analytic tool for water and fuel management issues. Here, to the fuel cell, a low-frequency signal was exploited and total harmonic distortion comprised in the ensuing signal was experimental in diverse circumstances. The THD was exploited to monitor and recognize the circumstances online like anode flooding, anode drying, hydrogen starvation, and cathode flooding established in the cell. This was performed by recognizing an indicator set frequencies to symbolize aforesaid serious circumstances. During experimental studies, it was revealed which frequency responses cause a high value of THD showing serious circumstances and offer a precise diagnostic technique to notice an even somewhat degraded condition.

In 2020, R. Hemalatha and M Ramasamy [3], developed the behavior of PQ and DSTATCOM compensation a hybrid controller. The RBF-NN algorithm was used by deduces the source current for compensation of DSTATCOM and minimum PQ issues. Exploiting DSTATCOM harmonic disturbances were minimized. The proposed hybrid controller algorithm was used to create constant DC voltage in the DC link capacitor of the proposed MLI.

In 2019, Carlo Ratto MD et al [4], worked on the THD Doppler process which was generally used to deal with the hemorrhoidal disease. It encompasses and presented to important alter in the therapeutic method to this circumstance. Through Doppler-guided dearterialization and minimization of hemorrhoidal prolapse using mucopexy its reason was to decrease the arterial overflow to the hemorrhoids. The dearterialization ought to be considered obligatory, whilst the mucopexy can be tailored consistent with the occurrence and evaluation of hemorrhoidal and mucosal prolapse. This process was generally secure, with chronic complications or the least risk of life-threatening events, and the minimum risk of recurrence.

In 2020, Michail Chalkiopoulos et al [5], addressed a performance optimization study of a thrusting manner using surface texturing. Bearing response computations was done using thermohydrodynamic modeling technique. A THD-optimal bearing design was computed, and a sensitivity analysis was done. 
The best model was estimated using a Thermo elastohydrodynamic technique, to enumerate the effects of the thermal deformation on tribological characteristics. Nevertheless, using thermal deformations bearing performance was substantially affected, leading to a decrease of thrust load and an enlarge coefficient of friction.

\section{Developed Hybrid Wind-Solar System Method for Efficient Power Generation}

The developed hybrid power generation system consists of 3 main systems such as wind and solar energy system producing system, full-bridge inverter, and DC to DC converters. In common, the wind and solar system encompass the full-bridge rectifier and DC to DC converters such as Cuk converters, buck-boost SEPIC. From both wind and solar systems the energy attained is linked to the 3-phase full-bridge inverter exploiting interphase transformer and converters namely SEPIC, Cuk, and buck-boost, converters.

To full-bridge inverter, the SPWM method presents control pulses. The inverter output is 3 phases sinusoidal AC voltage that is subsequently used to load using 3 phase's step-up transformer. Since a distinctiveness, $\mathrm{K}_{\mathrm{p}}$ and $\mathrm{K}_{\mathrm{i}}$ PI controller parameters, are optimized thus THD of the system acquires reduced. Both parameters selection is performed using a novel enhanced Shark smell optimizationalgorithm. Both the generators are linked with the 3-phase full-bridge inverter exploiting interphase converters and the transformer. Additionally, from the SPWM method, the full-bridge inverter attains control pulses to transform DC voltage to AC sinusoidal signal. At any instantaneous, voltages variations among DC voltages of 2 converters can be engrossed using an interphase transformer and assures standalone operation without any circulating current. Ultimately, generated power using high power quality and minimized THD is transported to the load from the transformer. Fig. 1 shows the architecture diagram of the developed hybrid power generating system.

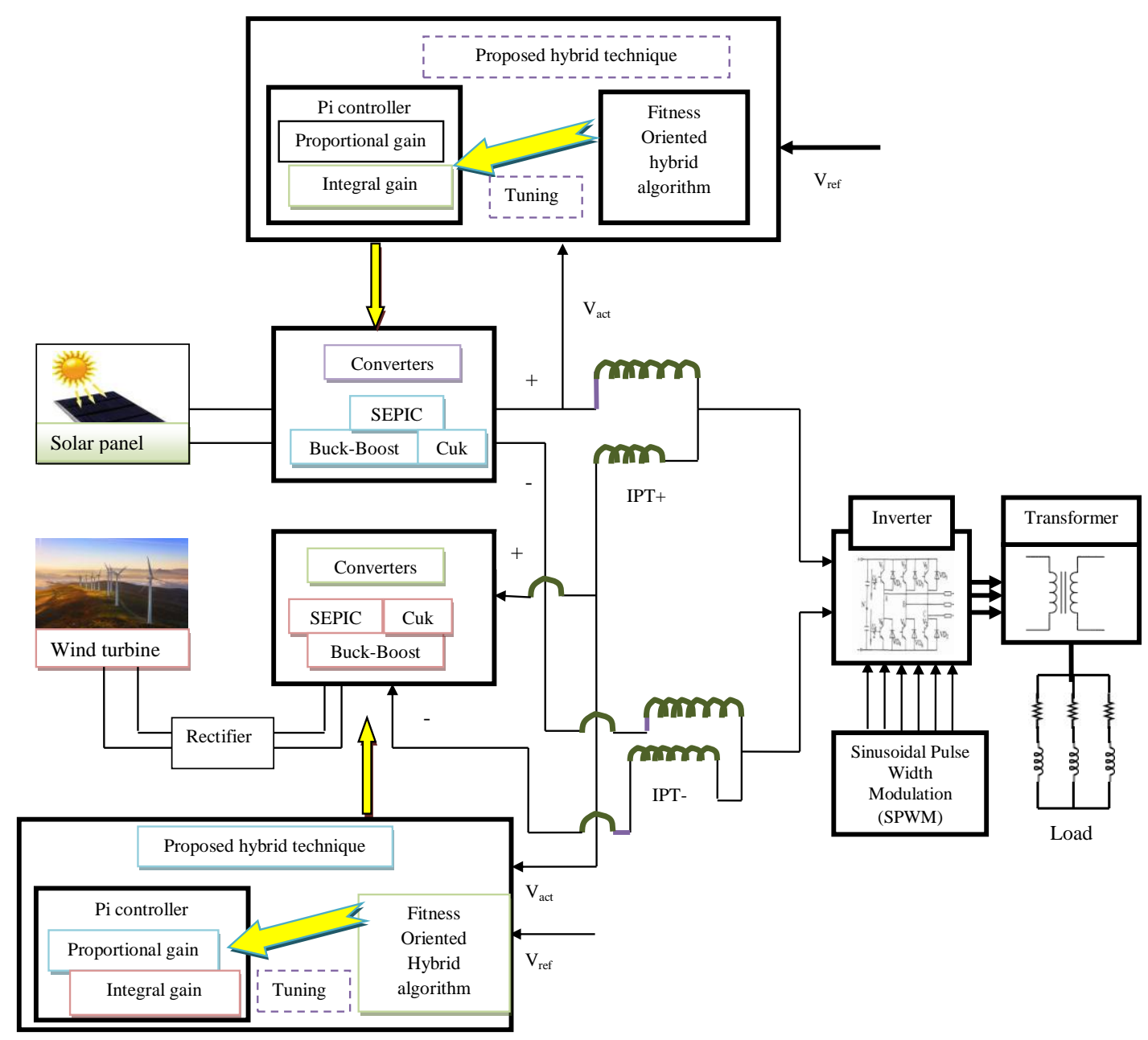

Fig. 1. Architecture diagram of the proposed hybrid model 
In this paper, 3 system models are described based on exploited converters namely SEPIC, buckboost, and cuk converter, correspondingly.

(i) SEPIC converter [7]: It fits in the DC to DC converter type and ensuing SEPIC voltage is done higher than, lesser than, or equivalent to that at its input. The n-channel MOSFET duty cycle controls the resultant SEPIC output voltage. The operations of SEPIC are similar to the Buck-Booster converter using additional benefits of generating non-inverted outputs. The non-inverted output is produced with the aid of a series capacitor with coupling the energy from input and outputs. The output voltage of the circuit drops down $0 \mathrm{~V}$ while the switch is in the off state. Also, the generated output voltage from SEPIC can be over or under regulator output and thus there are used in several battery charging applications.

(ii) Buck-Boost converter [6]: It is a DC to DC converter and an ensuing converter output voltage is equivalent or less than the input voltage. The output voltage magnitude is based upon completely on the duty cycle. Additionally, the buck boost converter is called the step up and a step-up transformer. The input power constructed equivalent to output power, using minimum conversion energy. The numerical value associating with the minimum conversion is stated in eq. (1). Also, the input voltage is lesser than the output voltage $\left(\operatorname{In}_{\text {Voltage }}<\right.$ Out $\left._{\text {voltage }}\right)$ and the input current is superior to the output current $\left(\mathrm{In}_{\text {current }}>\right.$ Out $\left._{\text {current }}\right)$ in the step-up model. In step down mode, the inverse operation of the step-up model happens that is $\left(\operatorname{In}_{\text {Voltage }}>\mathrm{Out}_{\text {voltage }}\right)$ and $\left(\mathrm{In}_{\text {current }}<\mathrm{Out}_{\text {current }}\right)$

$$
\text { Input power }\left(\operatorname{In}_{\text {power }}\right)=\text { Output power }\left(\text { Out }_{\text {power }}\right)
$$

The buck-boost converter is the integration of two converters (boost and bucks converter), and these converters, encompass the ability to produce a high range of output voltage than the input voltage. When the switch is in on-state, the inductor obtains the energy from the input and saves its energy based on the magnetic field. The exuding of energy takes place while the switch is unlocked.

(iii) Cuk Converter [8]: The Cuk converter output voltage is also superior or lesser than the input voltage based on the duty cycle.

The most important benefits of Cuk converters are minimum cost, minimum noise, and maximum effectiveness. Here, the basic Cuk converter, in that the input and output voltages are indicated as $\mathrm{In}_{\text {voltage }}$ and Out $\mathrm{voltage}_{\text {e }}$, correspondingly. The fundamental circuit of the Cuk converter comprises an input voltage source $\left(\mathrm{V}_{\mathrm{s}}\right)$, MOSFET switch $(\mathrm{Si})$, two capacitors $\left(\mathrm{C}_{1}, \mathrm{C}_{2}\right)$ out of that $\mathrm{C}_{1}$ is used for transporting energy, and $\mathrm{C}_{2}$ for storing energy. Additionally, 2 inductors $\left(\mathrm{L}_{1}\right.$ and $\left.\mathrm{L}_{2}\right)$ and an anti-parallel diode (Di) are in attendance. The current via the inductors $L_{1}$ and $L_{2}$ is indicated as $I_{1}$ and $I_{2}$. When the circuit switch (Si) is ON, the charging of the capacitor happens and the capacitor discharge happens in the OFF condition. For output voltage, the mathematical equation is indicated in Eq. (2), in that the duty ratio and the supply voltage are indicated by exploiting the phrase DiandEi , correspondingly. By exploiting eq.

(3) (4), the average load current and the energy saved in inductors are formulated. The load resistance is indicated as R. The least inductor value for the continuous conduction model is described as eq. (5) and (6). For the continuous conduction model, the least capacitor value is described in eq. (7) and (8).

$$
\begin{aligned}
& \mathrm{V}_{\text {out }}=-(\mathrm{Di} /(1-\mathrm{Di})) * \text { Ei Volts } \\
& \mathrm{I}_{\text {out }}=\mathrm{V}_{\text {out }} / \mathrm{R} \text { Ampere } \\
& \mathrm{Ei}=1 / 2 \mathrm{LI}^{2} \text { joules } \\
& \mathrm{L}_{1 \text { min }}=(1-\mathrm{Di})^{2} * \mathrm{R} / 2 \text { Di.f Henry } \\
& \mathrm{L}_{2 \max }=(1-\mathrm{Di})^{2} * \mathrm{R} / 2 . \mathrm{f} \text { Henry } \\
& \mathrm{C}_{1 \text { min }}=\mathrm{Di} / 2 \mathrm{f} . \mathrm{R} \text { Farad } \\
& \mathrm{C}_{2 \text { max }}=1 / 8 \mathrm{f} . \mathrm{R} \text { Farad }
\end{aligned}
$$

\section{Using the Proposed Method for Optimized PI Controller}

\subsection{PI Controller}

PI controller is a renowned controller that uses the ability to preserve precise set-points [9]. PI controller operation model is on basis of the amalgamation of 2 controller modes viz. integral and the proportional mode. For the PI controller, the logical term is attained from parameters of $\mathrm{K}_{\mathrm{p}}$ and $\mathrm{K}_{\mathrm{i}}$. The net integration model gain is changed using the model of $\mathrm{K}_{\mathrm{p}}$ in system and $\mathrm{K}_{\mathrm{i}}$ indicates independent and can 
be attuned. Using Eq. (9), the actual signal $(\mathrm{k}(\mathrm{t}))$ is determined and that the error signal is indicated as er(t). The Laplace transformation of eq. (9) is stated as eq. (10).

$$
\begin{aligned}
& \mathrm{k}(\mathrm{t})=\mathrm{K}_{\mathrm{p}} \cdot \operatorname{er}(\mathrm{t})+\mathrm{k}_{\mathrm{i} ;} \int \operatorname{er}(\mathrm{t}) \mathrm{dt} \\
& \mathrm{K}(\mathrm{s})=\mathrm{K}_{\mathrm{p}} \cdot \operatorname{Er}(\mathrm{s})+\mathrm{k}_{\mathrm{i}} ; \frac{\operatorname{Er}(\mathrm{s})}{\mathrm{s}}
\end{aligned}
$$

While the error $(\operatorname{er}(t)=0)$ is "0" in Eq. (9), the output of the controller obtains integral part value. In case, if the error $(\operatorname{er}(t) \neq 0)$ is not "0", integral phrase turns out to be saturated as it couldn't turn out to be negative. As stated in eq. (11), the transfer function of the PI controller.

$$
\mathrm{T}_{\text {fun }}=\mathrm{K}_{\mathrm{p}}+\left(\mathrm{K}_{\mathrm{i}} / \mathrm{s}\right)
$$

The mathematical equation relating to the time constraints for the PI controller is shown in eq. (12). The integral time constant is represented as $\zeta_{\mathrm{i}}$.

$$
\mathrm{K}(\mathrm{s})=\mathrm{K}_{\mathrm{p}} \cdot\left[1+1 / \mathrm{\zeta}_{\mathrm{i}}\right] \operatorname{Er}(\mathrm{s})
$$

Here, the minimization of THD is obtained by tuning both parameters of $\mathrm{K}_{\mathrm{p}}$ and $\mathrm{K}_{\mathrm{i}}$ in the PI controller.

\subsection{Proposed Optimization Algorithm}

SSO is a novel established meta-heuristic approach [10]. The most important objective in SSO is to attain an optimal global solution for a known optimization issue. This approach is based on the population that is in the initial step, a set of the exact population is chosen that is produced arbitrarily in search space. The main drawback of the conventional SSO approach is its infirmity in identifying global solutions in a few issues. Here, a hybrid configuration is presented to solve this issue. The aforesaid disadvantages of SSO are free parameters of SSO such as $\mathrm{P}_{1}, \mathrm{P}_{2}, \mathrm{P}_{3}, \lambda_{\mathrm{m}}$, and $\beta_{\mathrm{m}}$. Here, we employed the WCO method is another novel optimization method introduced in [11]. This approach is enthused by competitions in the FIFA world cup. This method is used to improve the global capability of SSO. Here, the WCO method is used to generate free parameters of SSO such as $\mathrm{P}_{1}, \mathrm{P}_{2}, \mathrm{P}_{3}, \lambda_{\mathrm{m}}$, and $\beta_{\mathrm{m}}$, that is restricted in the interval $(0,1]$ that is represented as follows:

$$
\begin{aligned}
& 0<\lambda_{\mathrm{m}}<1 \\
& 0<\beta_{\mathrm{m}}<1 \\
& 0<\mathrm{P}_{1}, \mathrm{P}_{2}, \mathrm{P}_{3} \leq 1
\end{aligned}
$$

At this stage, the input population for $\mathrm{WCO}$ can be a $5 \times \mathrm{N}$ population whereas these five parameters are optimized as follows:

$$
\begin{array}{r}
{\left[\mathrm{y}_{1}^{\mathrm{m}}, \mathrm{y}_{2}^{\mathrm{m}}, \mathrm{y}_{3}^{\mathrm{m}}, \mathrm{y}_{4}^{\mathrm{m}}, \mathrm{y}_{5}^{\mathrm{m}}\right]=\left[\lambda_{\mathrm{m}}, \beta_{\mathrm{m}}, \mathrm{P}_{1}, \mathrm{P}_{2}, \mathrm{P}_{3}\right]} \\
\mathrm{C}=\left[\begin{array}{lllll}
\mathrm{x}_{\mathrm{c} 1,1} & \mathrm{x}_{\mathrm{c} 2,1} & \mathrm{x}_{\mathrm{c} 3,1} & \mathrm{x}_{\mathrm{c} 4,1} & \mathrm{x}_{\mathrm{c} 5,1} \\
\mathrm{x}_{\mathrm{c} 1,2} & \mathrm{x}_{\mathrm{c} 2,2} & \mathrm{x}_{\mathrm{c} 3,2} & \mathrm{x}_{\mathrm{c} 4,2} & \mathrm{x}_{\mathrm{c} 5,2} \\
\mathrm{x}_{\mathrm{c} 1,3} & \mathrm{x}_{\mathrm{c} 2,3} & \mathrm{x}_{\mathrm{c} 3,3} & \mathrm{x}_{\mathrm{c} 4,3} & \mathrm{x}_{\mathrm{c} 5,3} \\
\mathrm{x}_{\mathrm{c} 1,4} & \mathrm{x}_{\mathrm{c} 2,4} & \mathrm{x}_{\mathrm{c} 3,4} & \mathrm{x}_{\mathrm{c} 4,4} & \mathrm{x}_{\mathrm{c} 5,4}
\end{array}\right]
\end{array}
$$

In eq. (17), $C$ denotes the continent, $y_{i}^{m}$ denotes the system variables, $y_{i, j}$ denotes the $i^{\text {th }}$ team of $j^{\text {th }}$ country $\mathrm{N}_{\mathrm{var}}$ denotes the count of variable dimensions and $\mathrm{Q}$ indicates continents quantity. As same as other population-based approaches WCO initiates with an arbitrary vector of solution. In this approach the rating parameter is attained by the Rank is defined as below:

$$
\begin{array}{r}
\text { Rank }=\frac{(\alpha \times \sigma+\bar{Y})}{2} \\
\bar{Y}=\frac{1}{n} \sum_{i=1}^{n} Y_{i} \\
\sigma=\sqrt{\frac{1}{n-1} \sum_{i=1}^{n}\left(Y_{i}-\bar{Y}\right)^{2}}
\end{array}
$$

In eq. (19), $\mathrm{n}$ indicates the team's quantity, $\alpha$ indicates a tunable parameter between 0 and 1 , and $\overline{\mathrm{Y}}$ indicates the average and $\sigma$ indicates the standard deviation of the $Y$, correspondingly. In WCO, PlayOff is one more important parameter that creates global optimization that is the exploration segment of approach powerful. In the approach, the Play-off parameter is attained as defined as follows: 


$$
\text { pop }=\left[\mathrm{Y}_{\text {best }}, \mathrm{Y}_{\text {rand }}\right]
$$

In eq. (21), $Y_{\text {rand }}$ indicates a random quantity and pop indicates the next population of the approach using size $\mathrm{N} \times \mathrm{M}$.

$$
\frac{1}{2} \times \mathrm{ac} \times\left(\mathrm{U}_{\mathrm{b}}-\mathrm{L}_{\mathrm{b}}\right)<\mathrm{Y}_{\text {best }} \times \frac{1}{2} \times \mathrm{ac} \times\left(\mathrm{U}_{\mathrm{b}}-\mathrm{L}_{\mathrm{b}}\right)
$$

In eq. (22), $\mathrm{U}_{\mathrm{b}}$ and $\mathrm{L}_{\mathrm{b}}$ indicates the upper and the lower restrictions of an issue and ac indicates free parameter among $\mathrm{L}_{\mathrm{b}}$ and $\mathrm{U}_{\mathrm{b}}$. Additional information regarding the WCO is attained from [12]. Thoroughly, the inspiration of the developed algorithm is to integrate the benefits of WCO and SSO approaches. By manufacturing the operators of the WCO approach in the conventional SSO approach, a real trade-off among exploration and exploitation abilities was done. Even though, both algorithms have their own imperfections and advantages. As aforesaid, a great issue in the SSO approach is that its exploration phrase is nearly feeble. This is because of various unrevealed parameters $\left(\mathrm{P}_{1}, \mathrm{P}_{2}, \mathrm{P}_{3}, \lambda_{\mathrm{m}}\right.$, and $\beta_{\mathrm{m}}$ ) which must be chosen manually. Due to the benefits of WCO in exploration, it is exploited to decide SSO unrevealed parameters. Hence, the fundamental scheme in the proposed algorithm is to the integration of the capability of teams' competition in the WCO approach and the shark's prey hunting in the SSO approach. Due to the WCO and SSO, both are population-based approaches; the integrated proposed approach is additionally a population-based approach that begins to discover a global solution. Fig 2 shows a flow chart of the proposed model.

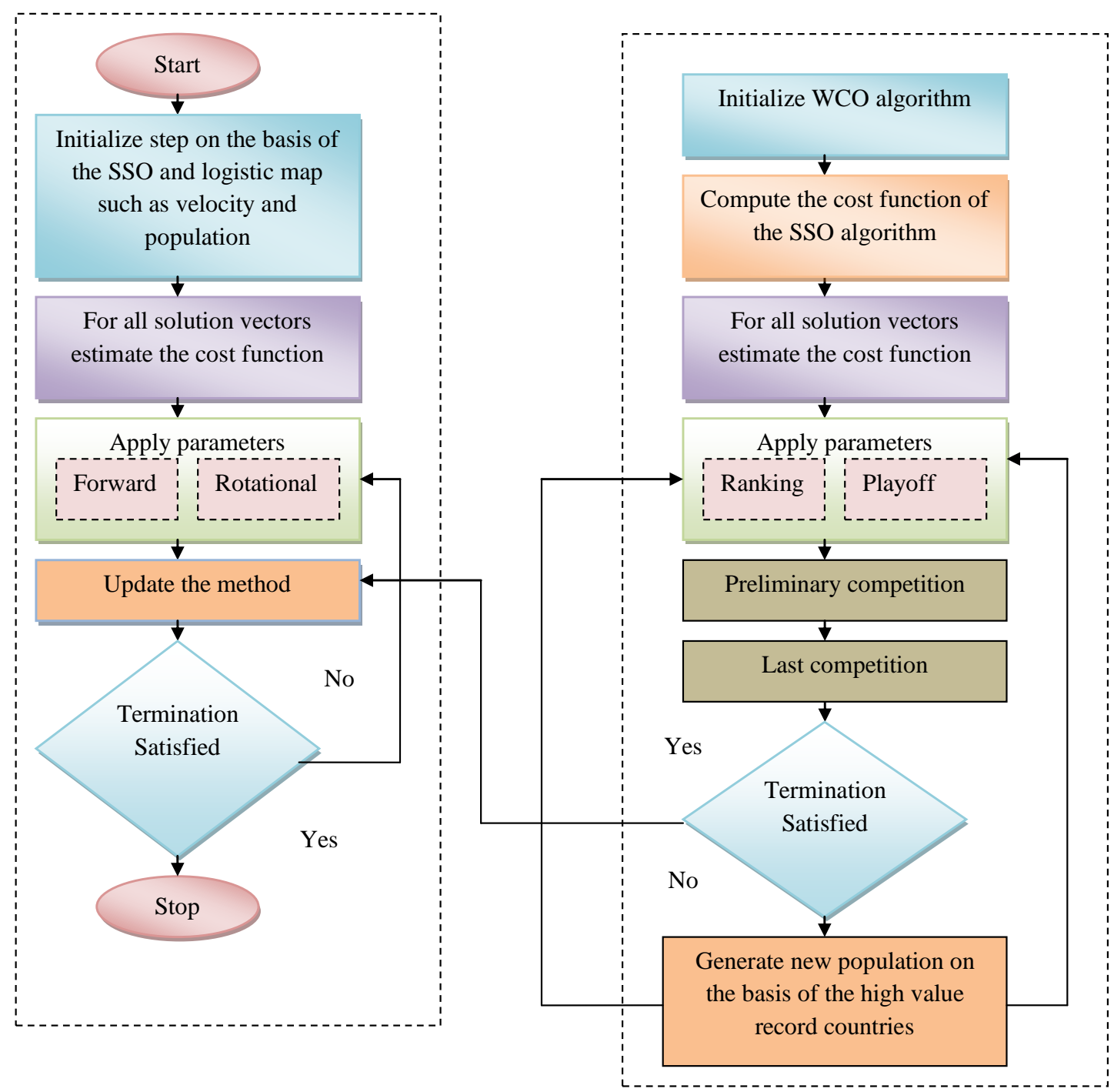

Fig. 2. Flow chart of a proposed hybrid technique 


\section{Results and Discussions}

\subsection{Experimental Procedure}

The developed hybrid power generating system method using optimized PI was executed in MATLAB 2018 a, and the ensuing of every examination was experimental. The developed technique was modelled in the Buck-Boost, $3 \mathrm{Cuk}$, and SEPIC converters, which were evaluated regarding THD. For this analysis, the control pulse of Buck converter, Cuk converter, and SEPIC converter from the initial 500 control pulse lies among the times $1 * 10-3$ to $4 * 10-3$. The developed technique was analyzed with the conventional models such as GA [13], GWO [16], PSO [14], ROA [17], and FF [15], regarding the THD load voltage, and error.

\subsection{Performance Analysis}

Table 1 shows the overall analysis of the THD load voltage of the proposed method. The THD of the three converters such as Buck converter, Cuk, SEPIC converter for the developed technique are minimized and are demonstrated via this analysis.

Fig. 3 demonstrates the graphical representation of the error signal for the Buck converter, Cuk, SEPIC converter. Here, complete evaluation of Buck converter, Cuk, SEPIC converter regarding error is shown, which is very low compared to the conventional models.

Table 1: Analysis of the developed and existing techniques with respect to THD voltage

\begin{tabular}{llll}
\hline Methods & Buck-Boost converter & Cuk converter & SEPIC converter \\
\hline GA & -23.8260209 & -23.8269226 & -25.23 \\
PSO & -24.8260232 & -23.8269226 & -27.267 \\
FF & -27.8260209 & -24.8269226 & -25.23 \\
GWO & -27.8260209 & -24.8269226 & -25.23 \\
ROA & -27.8258658 & -25.827702 & -27.826 \\
proposed method & -26.8360232 & -27.8242223 & -27.826 \\
\hline
\end{tabular}

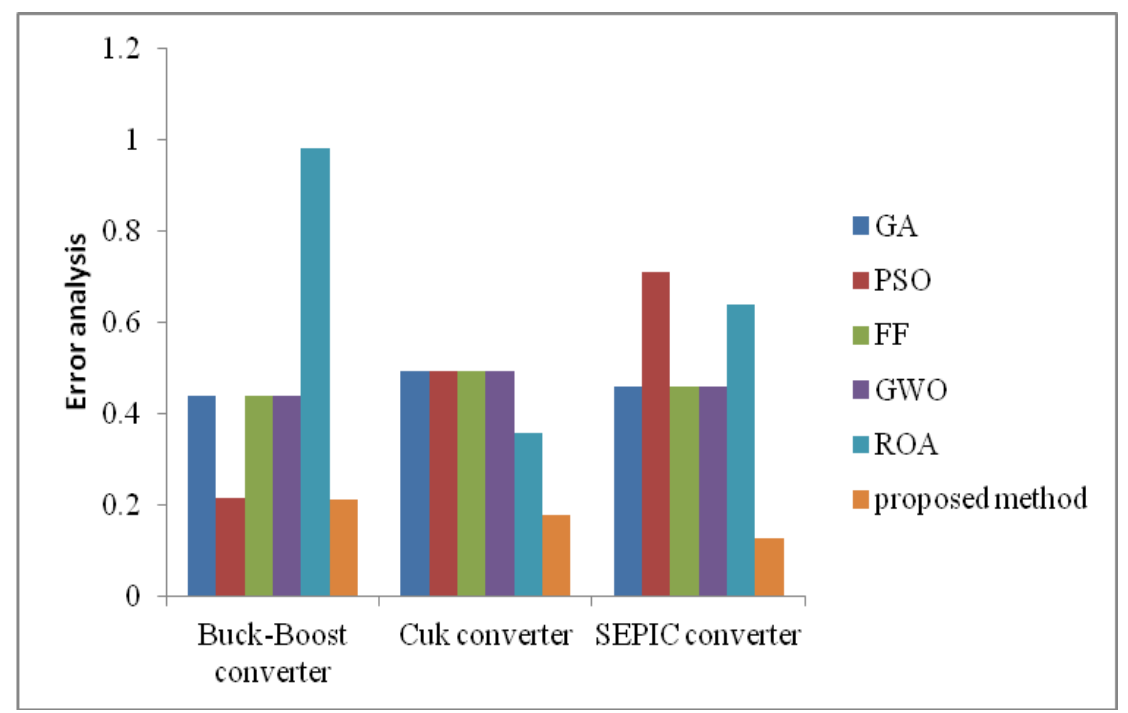

Fig. 3. Analysis of developed and existing techniques with respect to error analysis

\section{Compliance with Ethical Standards}

Conflicts of interest: Authors declared that they have no conflict of interest.

Human participants: The conducted research follows the ethical standards and the authors ensured that they have not conducted any studies with human participants or animals. 


\section{Conclusion}

In this work, the minimization of the THD using the presenting a hybrid power generation system was focused. The developed hybrid power generation system covered wind and converters, full-bridge inverter, and a solar power generation system. The developed and conventional methods were experimented by linking DC to DC converters such as Cuk converter, SEPIC, buck-boost to the system. In the developed technique, THD was reduced by optimizing Integral and the proportional gain parameters of the PI controller. The optimization of Integral and proportional gain parameters was attained using the Hybrid SSO-WCO approach. In the end, a performance-based evaluation was done among developed and the conventional methods such as GA, FF, PSO, GWO and ROA regarding the error and THD load voltage for each of converters.

\section{References}

[1] R. Gunasekaran, C. Karthikeyan,"Nonlinear Transformational Optimization (NTO) technique based Total Harmonics Distortion (THD) reduction of line to line voltage for multi-level inverters", Microprocessors and Microsystems,Volume 74,April 2020.

[2] N. J. Steffy, S. Vinod Selvaganesh, Madan Kumar L, A. K. Sahu," Online monitoring of fuel starvation and water management in an operating polymer electrolyte membrane fuel cell by a novel diagnostic tool based on total harmonic distortion analysis", Journal of Power Sources, Volume 40415, November 2018,Pages 81-88.

[3] R. Hemalatha, M Ramasamy,"Microprocessor and PI controller based three phase CHBMLI based DSTATCOM for THD mitigation using hybrid control techniques",Microprocessors and Microsystems,Volume 76,July 2020.

[4] Carlo Ratto, Angelo Parello, Francesco Litta, Veronica De Simone, Angelo Marra,"The evolving role of THD in hemorrhoids", Seminars in Colon and Rectal Surgery,Volume 30, Issue 4, December 2019.

[5] Michail Chalkiopoulos, Anastassios Charitopoulos, Michel Fillon, Christos I. Papadopoulos,"Effects of thermal and mechanical deformations on textured thrust bearings optimally designed by a THD calculation method",Tribology, International, Volume 148,August 2020.

[6] K. I. Hwu and T. J. Peng, "A Novel Buck-Boost Converter Combining KY and Buck Converters," in IEEE Transactions on Power Electronics, volume. 27, number. 5, page no. 2236-2241, 2012.

[7] J. Yang and H. Do, "Bridgeless SEPIC Converter With a Ripple-Free Input Current," in IEEE Transactions on Power Electronics, vol. 28, no. 7, pp. 3388-3394, July 2013.

[8] K. M. Smedley and S. Cuk, "Dynamics of one-cycle controlled Cuk converters," in IEEE Transactions on Power Electronics, volume. 10, number. 6, page no. 634-639, November. 1995.

[9] Musa Idi,Mohammed Ahmed,Borskghinchin Daniel Halilu,Abdulkadir Abubakar Sadiq,"Proportional Integral (PI) Controller for a Process Plant System",International Journal of Engineering Research \& Technology (IJERT), Volume. 4, no 01,January-2015.

[10] O. Abedinia, N. Amjady, A. Ghasemi, A new metaheuristic algorithm based onshark smell optimization, Complexity, vol. 21,no.5, pp. 97-116, 2016.

[11] N. Razmjooy, A. Madadi, M. Ramezani, Robust control of power systemstabilizer using world cup optimization algorithm, Int. J. Inform. Secur. Syst.Manag, vol. 5 , no.1, 7, 2017.

[12] N. Razmjooy, M. Khalilpour, M. Ramezani, A New Meta-HeuristicOptimization Algorithm Inspired by FIFA World Cup Competitions: Theoryand Its Application in PID Designing for AVR System, J. Control Autom. Elect.Syst, volume.27, number.4, page no. 419-440, 2016.

[13] Ramschak E, Peinecke V, Prenninger P, Schafler T, Hacker V. J Power Sources 2006;157:837e40.

[14] JohnMcCall, " Genetic algorithms for modelling and optimisation", Journal of Computational and Applied Mathematics, volume. 184, number. 1, page no. 205-222, 2005.

[15] M.R.Tanweer, S.Suresh, and N.Sundararajan, " Self regulating particle swarm optimization algorithm", Information Sciences, vol. 294, pp. 182-202, 2015

[16] IztokFister, IztokFisterJr, Xin-SheYang and JanezBrest, "A comprehensive review of firefly algorithms", Swarm and Evolutionary Computation, volume. 13, page no. 34-46, 2013.

[17] Seyedali Mirjalili, Seyed Mohammad Mirjalili, Andrew Lewis, "Grey Wolf Optimizer", Advances in Engineering Software, volume.69, page no, 46-61, 2014.

[18] Binu and Kariyappa," RideNN: A New Rider Optimization Algorithm-Based Neural Network for Fault Diagnosis in Analog Circuits", IEEE Transactions On Instrumentation And Measurement, page no.1-25, 2018.

[19] Sarath K S, Dr S Sekar,"An Optimal Design of LLC Resonant Converter using FireFly Algorithm based Parameter Optimization Approach",Journal of Computational Mechanics, Power System and Control (JCMPS), Volume 2, Issue 1, January 2019

[20] V.Tejaswini and Dr.D.Susitra,"Hybrid PSO-WOA for Solving ORPD Problem under Unbalanced Conditions",Journal of Computational Mechanics, Power System and Control (JCMPS), Volume 2, Issue 2, April 2019 . 